\title{
Postabortion care services in Kenya: Baseline findings of an operations research study
}

Julie Solo

Population Council

Deborah L. Billings

Follow this and additional works at: https://knowledgecommons.popcouncil.org/departments_sbsr-rh

Part of the Family, Life Course, and Society Commons, Health Services Research Commons, International Public Health Commons, and the Women's Health Commons How does access to this work benefit you? Let us know!

\section{Recommended Citation}

Solo, Julie and Deborah L. Billings. 1997. "Postabortion care services in Kenya: Baseline findings of an operations research study," Africa OR/TA Project II. Nairobi: Population Council. 


\section{Postabortion Care in Kenya:}

\section{Baseline Findings of an Operations Research Study}

March 1997

Julie Solo, M.P.H., The Population Council, Africa OR/TA Project II Deborah L. Billings, Ph.D., IPAS

Division of Family Health, Ministry of Health 


\section{TABLE OF CONTENTS}

ACKNOWLEDGMENTS . . . . . . . . . . . . . . . . . . . . . . . .

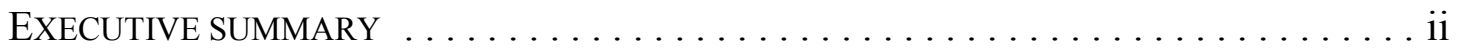

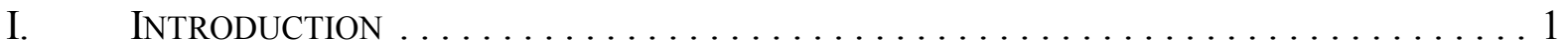

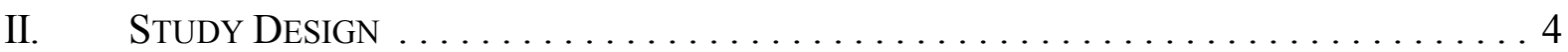

III. Field Work AND Data COLLECTION $\ldots \ldots \ldots \ldots \ldots \ldots \ldots \ldots \ldots \ldots$

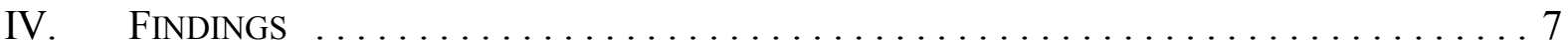

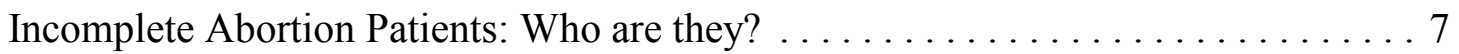

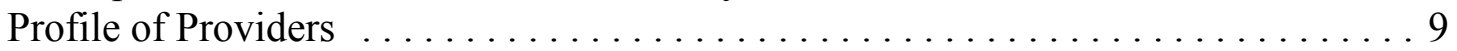

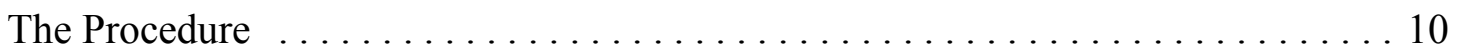

Duration of Patient Stay on the Gynae Ward . . . . . . . . . . . . . . . . 12

Pain Control Practices ................................ 14

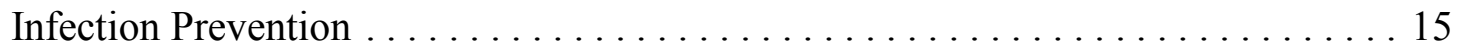

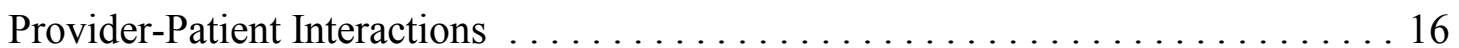

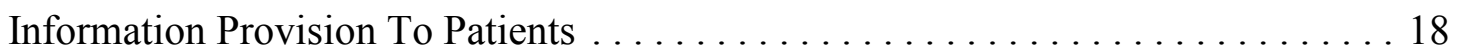

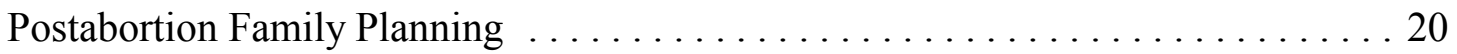

The Experience Of Nyeri Provincial General Hospital . . . . . . . . . . . . . . 21

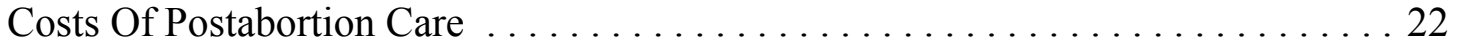

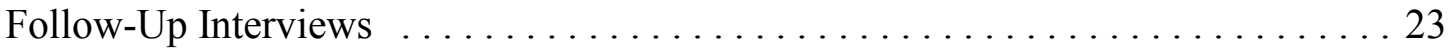

V. DisSEMINATION WORKSHOP AND FUtURE PlANS $\ldots \ldots \ldots \ldots \ldots \ldots \ldots \ldots . \ldots . \ldots$ 


\section{ACKNOWLEDGMENTS}

The authors would like to express their gratitude to the providers at the hospitals who gave us so much of their time, and who continue to work hard, often under difficult conditions, to improve postabortion care services.

We would also like to thank the women who allowed us to speak at length with them, even at such a difficult time, and who provided us with so much valuable information.

This study could not have been conducted without the excellent work of the researchers: Njeri Kagondu, Eugenia King'ori, Dorcas Kungu, Mumbi Kyalo, Elizabeth Mugwe, Millie Obel, Rena Otieno, Agnes Rinyiru and Lilian Rono. We thank them for their commitment to this project, and for the many hours they spent collecting this information at the hospitals.

Numerous colleagues at The Population Council, IPAS and the Division of Family Health have given us valuable input to this report and to the project. In particular, we thank Ian Askew and Esther Muia of The Population Council and Janie Benson of IPAS.

Finally, we gratefully acknowledge the support of USAID, without whom this project would not have been possible. 


\section{EXECUTIVE SUMMARY}

In Kenya, as throughout the world, the health consequences of unsafe abortion ${ }^{1}$ for women of reproductive age are significant. Hospital-based studies in Nairobi have shown that unsafely induced abortion accounts for as much as 35 percent of pregnancy-related mortality and at least 50 percent of hospitals' gynecological admissions. ${ }^{2}$ These figures underestimate the true extent of the problem, however, since they represent only those women who make it to public hospitals for treatment; women who seek services from private providers or through other means are excluded from these estimates, as are women who do not seek or who lack access to services. In addition, these figures tend to focus on induced abortion and therefore exclude women arriving at public facilities with complications resulting from a spontaneous abortion.

The concept of postabortion care has gained wide acceptance as one model of providing comprehensive care to women suffering from abortion complications. Postabortion care consists of the following three elements: 1) emergency treatment services for complications of spontaneous or unsafely induced abortion; 2) postabortion family planning counselling and services and 3) links between emergency abortion treatment services and comprehensive reproductive health care. One way to improve emergency treatment is through the use of manual vacuum aspiration (MVA), a technique that has been shown to be safer and less costly then dilation and curettage $(\mathrm{D} \& \mathrm{C})$.

Integration of these three components is rarely found in public health care facilities throughout the world, including Kenya. There is therefore a need to determine how to create these linkages to improve the quality of existing postabortion care services. In order to address this need, The Population Council's Africa Operations Research and Technical Assistance Project II is collaborating with IPAS, the Kenyan Ministry of Health $(\mathrm{MOH})$ and the Family Planning Association of Kenya (FPAK) on a project to test three different models of linking emergency treatment of incomplete abortion and family planning services in six $\mathrm{MOH}$ hospitals in Kenya.

\section{GENERAL STUDY DESIGN}

Pre-intervention data collection (Feb-June, 1996)

$\downarrow$

Intervention: trainings; facility upgrades; and reorganization of services (Sept-Dec, 1996)

Post-intervention data collection (March-April, 1997)

\section{INTERVIEWS CONDUCTED IN SIX MOH HOSPITALS}

- 481 incomplete abortion patients interviewed after receiving treatment and prior to discharge from hospital: 63 percent treated with MVA and 37 percent with D\&C.

1 Defined by the World Health Organization as a procedure for terminating an unwanted pregnancy either by persons lacking necessary skills or in an environment lacking the minimal medical standards or both.

2

Lema et al 1989., Rogo 1993 
- $\quad 140$ providers interviewed, including OB/GYN Specialists, Doctors and Nurses working on the gynae ward, in the $\mathrm{MCH} / \mathrm{FP}$ clinic and in the theatre.

\section{MAIN FindingS}

Characteristics of incomplete abortion patients. Patients ranged in age from 15 to 46, with 61 percent falling between 20 and 29. One third had no children, while almost one quarter had over two children. Seventy-one percent indicated that they were married (either monogamous or polygamous), and 23 percent said that they were single.

- Incomplete abortion patients are of a wider variety than providers described when asked to describe the "typical" patient, pointing to the misconceptions about these patients.

Duration of patient stay on gynae ward. Patients' reports of the time they waited for treatment once admitted to the gynae ward varied by the type of procedure used in the treatment of incomplete abortion. While over half of D\&C patients ( 56 percent) were treated within 12 hours, the same can only be said for 19 percent of MVA patients. Thirty-eight percent of MVA patients waited more than two days, while only 15 percent of $\mathrm{D} \& \mathrm{C}$ patients waited for this long. Studies have typically shown that MVA shortens total hospital stay, primarily because it can be done as an outpatient procedure without the use of general anesthesia. However, waiting time was affected more by the organization of services and supplies available at each hospital than by the type of treatment used.

- $\quad$ The fact that MVA patients are generally waiting long periods to receive treatment indicates that the organization of services, and not just the technology itself, is important for shortening hospital stay.

Pain and pain control practices. Roughly one-fifth (19 percent) of all patients were given some sort of pain medication before or during the procedure; this included only 44 percent of D\&C patients and three percent of MVA patients. Of the women who were awake during the procedure, 97 percent reported that they experienced pain. About two-thirds indicated that the pain was "extreme", one-fourth "moderate", and ten percent "minimal". In some cases, the lack of pain control seems to be linked to negative and judgmental attitudes held by some providers toward women being treated for an incomplete abortion.

- $\quad$ Providers suggested ways in which pain could be reduced, including the need to divorce personal biases from their treatment practices and the need to provide counselling to women before, during and after the procedure.

Infection prevention (IP). IP is an essential component of health care, to protect both the patient and the provider. Providers were asked a series of questions to assess their knowledge and practices regarding the reuse of MVA equipment.

- $\quad$ There was a clear need to improve IP practices in the handling of MVA equipment. The trainings conducted for the hospitals included a strong focus on this area. 
Provider-patient interactions. When providers were asked to describe provider-patient interactions at their hospital, 46 percent described them as "poor", 36 percent stated that relations were "good" and 15 percent said "it depends", often differentiating between spontaneous and induced abortion cases. An important point to highlight is that provider attitudes play a significant role in the quality of care received by patients and that negative provider attitudes can adversely affect their provision of services.

- $\quad$ Providers identified many ways to address these negative attitudes, including training, setting up a forum for staff dialogue, motivating staff through improved supply provision and increases in pay, and being polite and understanding to patients rather than judgmental.

Information provision to patients. In general, few patients were given any information about the procedure itself, about their general health status, or about their return to fertility. Only 18 percent were told what was going to happen to them during the procedure; two percent of patients indicated that they received information on problems that they might experience for which they should return to a health facility; and 16 percent were told by a provider that they could have an almost immediate return to fertility.

- In addition to creating linkages to postabortion family planning counselling, it is essential that general counselling of incomplete abortion patients also be improved.

Postabortion family planning. At five of the hospitals, a total of only seven percent of patients received family planning information, while at Nyeri (a site which began implementing services before the interventions were officially introduced) almost all patients (98 percent) received postabortion family planning counselling. While only 22 percent decided to begin using contraception at the five hospitals, at Nyeri this number was 62 percent. Of the 22 percent who decided to use family planning, three percent received a method, while at Nyeri almost all (97 percent) who decided to begin using received a family planning method.

- $\quad$ There is clearly a need and a demand for postabortion family planning, as indicated from both patient and provider interviews. Of patients who did not receive family planning information, the majority (89 percent) would have liked to have received it. While almost all providers (97 percent) said that family planning information should be given following treatment, only 21 percent said that this is routinely done at their hospital (excluding Nyeri).

\section{NEXT STEPS}

Trainings in MVA and postabortion family planning were completed at the six hospitals, incorporating the issues raised in the baseline findings. Findings from the complete study will assist the $\mathrm{MOH}$ in improving the quality of care received by postabortion patients and will inform planning for expansion of postabortion care services throughout the country. 


\section{INTRODUCTION}

Abortion remains one of the most controversial topics of our time. Because of the strong feelings attached to the issue, it has been very difficult to frame abortion services-- whether they be provision of legal induced abortion or treatment of incomplete abortion-- in a strictly health context. Often the extreme health impact gets lost in the rhetoric and the battle over whether and how to legalize or liberalize abortion legislation. Meanwhile, as this debate continues, 20 million women undergo unsafe abortions every year ${ }^{3}$, defined by the World Health Organization as a procedure for terminating an unwanted pregnancy either by persons lacking necessary skills or in an environment lacking the minimal medical standards or both. ${ }^{4}$ This results in high maternal mortality and morbidity. Though difficult to estimate due to the illegal nature of abortion in most countries, estimates of abortion related deaths seem to fall between $20-40$ percent of all maternal deaths worldwide. ${ }^{5}$ Approximately 70,000 women die annually from complications related to unsafe abortions, ${ }^{6}$ most of these deaths occurring in the developing world.

In Kenya, as throughout the world, the health consequences of unsafe abortion for women of reproductive age are significant. Hospital-based studies in Nairobi have shown that unsafely induced abortion accounts for as much as 35 percent of pregnancy-related mortality and at least 50 percent of hospitals' gynecological admissions. ${ }^{7}$ These figures underestimate the true extent of the problem, however, since they represent only those women who make it to public hospitals for treatment; women who seek services from private providers or through other means are excluded from these estimates, as are women who do not seek or who lack access to services. In addition, these figures tend to focus on induced abortion and therefore exclude women arriving at public facilities with complications resulting from a spontaneous abortion.

The concept of postabortion care has gained wide acceptance as one model of providing comprehensive care to women suffering from abortion complications. Postabortion care consists of the following three elements: 1) emergency treatment services for complications of spontaneous or unsafely induced abortion; 2) postabortion family planning counselling and services and 3) links between emergency abortion treatment services and comprehensive reproductive health care. The premise is that improving the quality and accessibility of emergency treatment will reduce rates of morbidity and mortality. One way to improve emergency treatment is through the introduction of manual vacuum aspiration (MVA), a

3 Abortion: Tabulation of Available Data on the Frequency and Mortality of Unsafe Abortion, 2nd Ed. World Health Organization, (WHO), Geneva, 1994

$4 \quad$ The Prevention and Management of Unsafe Abortion, Report of a Technical Working Group, World Health Organization, (WHO), Geneva, 1993

5 Coeytaux, F., A. Leonard \& C. Bloomer "Abortion” in M. Koblinsky, J. Timyan \& J. Gay (eds) The Health of Women: A Global Perspective, Westview Press, Boulder. 1993 Abortion: Tabulation of Available Data on the Frequency and Mortality of Unsafe Abortion

7 Lema V., S. Kamau and K. Rogo. Epidemiology of Abortion in Kenya. The Center for the Study of Adolescence. Nairobi, Kenya. 1989. Rogo, Khama. Induced Abortion in Kenya. Paper prepared for IPPF. Center for the Study of Adolescence. Nairobi, Kenya. 1993 
technique that has been shown to be safer and less costly than dilation and curettage (D\&C) ${ }^{8}$. Anecdotal evidence from this current study illustrates the high prevalence of repeat abortion. Providing the second element, postabortion family planning, will enable women to avoid repeat unwanted pregnancies and therefore also avoid unsafe abortions. It will also allow women who have had spontaneous abortions to rest and wait before their next pregnancy, should they choose to do so. Links to other reproductive health care services will further help to improve women's health.

These services are rarely integrated in health care settings throughout the world, including Kenya. ${ }^{9}$ There is therefore a need to determine how to best offer and structure these services in a variety of settings. In order to address this need, The Population Council's Africa Operations Research and Technical Assistance Project II is collaborating with IPAS, the Kenyan Ministry of Health (MOH) and the Family Planning Association of Kenya (FPAK) on a project to test three different models of integrating postabortion family planning services with the treatment of incomplete abortion. This study focuses on the first two elements of postabortion care. Phase one of this study was undertaken in 1995 to select sites at which to test the models. After visiting 18 hospitals in Kenya, six were selected on the basis on the following criteria: caseload of incomplete abortions at the facility; adequate infrastructure in terms of space, supplies and equipment; and provider perspectives. ${ }^{10}$

Table 1: Models to be tested at each hospital

\begin{tabular}{||l|c|l||}
\hline \multicolumn{1}{|c|}{ MVA Sites } & model & \multicolumn{1}{c||}{ D\&C Sites } \\
\hline \hline $\begin{array}{l}\text { Coast Provincial General } \\
\text { Hospital, Mombasa }\end{array}$ & $\begin{array}{c}\text { fp services provided on the ward by gynae ward } \\
\text { staff }\end{array}$ & $\begin{array}{l}\text { New Nyanza Provincial } \\
\text { General Hospital, } \\
\text { Kisumu }\end{array}$ \\
\hline $\begin{array}{l}\text { Nakuru Provincial } \\
\text { General Hospital }\end{array}$ & fp services provided on ward by mch/fp clinic staff & Meru District Hospital \\
\hline $\begin{array}{l}\text { Eldoret District Hospital } \\
\text { fp services provided in mch/fp clinic by mch/fp } \\
\text { staff }\end{array}$ & $\begin{array}{l}\text { Nyeri Provincial General } \\
\text { Hospital }\end{array}$ \\
\hline
\end{tabular}

Table 1 indicates the sites chosen as well as the models to be tested at each site. The models vary by where the services are offered and which staff offer the services:

- $\quad$ model \#1: $\quad$ postabortion family planning is provided on the gynae ward by ward staff;

- $\quad$ model \#2: $\quad$ services are provided on the ward, but by family planning clinic staff;

Greenslade, F., A. Leonard, J. Benson, J. Winkler, V. Henderson. Manual Vacuum Aspiration: A Summary of Clinical \& Programmatic Experience Worldwide. IPAS. 1993

9 One notable exception is the High Risk Clinic at Kenyatta National Hospital in Nairobi, Kenya. This clinic provides family planning counselling to both postabortion and postpartum adolescents.

10 Solo, Julie, Esther Muia and Khama Rogo, Testing alternative approaches to providing integrated treatment of abortion complications and family planning in Kenya: Findings from Phase I. The Population Council, Nairobi, August 1995 
- $\quad$ model \#3: incomplete abortion patients are escorted to the family planning clinic where they receive family planning counselling and methods.

Sites are also defined as MVA and D\&C sites, depending on the primary evacuation method used by providers to treat women, so that comparisons could be made between those hospitals where MVA services need to be upgraded and postabortion family planning services added and those hospitals in which both MVA and postabortion family planning services need to be added. ${ }^{11}$ Sites were designated as either MVA or D\&C sites based on data collected in phase I of the project which showed the primary method used in evacuations. As described below, these designations were not always completely accurate, due to a variety of reasons. This will be taken into account during the final analysis of this project, particularly for its implications on the feasibility and cost of providing postabortion services.

Each site has unique characteristics in the organization of incomplete abortion treatment services. The following provides a brief picture of how services were organized in the pre-intervention period at each site.

- Coast Provincial General Hospital, Mombasa. In Mombasa, most patients are treated with MVA. Patients are admitted to the gynae ward where they wait for treatment. MVA is done in the VSC minor theatre without any pain medication given before or during treatment. Patients wait for other procedures to be completed (i.e., TL and Norplant ${ }^{\mathbb{B}}$ implants), and then they are escorted to the theatre as a group. After each patient has been evacuated, they are then brought back as a group to the ward where they rest and are then discharged. Because of the typically long wait for treatment, patients were in hospital for an average of about two days. During the intervention period, Coast General has created both an MVA and a postabortion family planning counselling room on the gynae ward.

- Nakuru Provincial General Hospital. Nakuru uses MVA for treatment of incomplete abortion patients. Patients are admitted to the gynae ward and are treated in a small room on the ward. Though they have a room on the ward, patients still often wait for treatment due to overcrowding, understaffing, and shortages of supplies. The supplies include consumables, such as JIK and cotton wool, which patients must buy for treatment, and MVA kits. At the time of the preintervention data collection, Nakuru was operating with only one kit, which limited the efficiency and safety with which they could treat patients.

- Eldoret District Hospital. Eldoret is a teaching hospital. Though classified as an MVA site, in the preintervention period of this study, about half of the patients were treated with D\&C due to shortages of MVA instruments. Patients are admitted to the gynae ward, where there is an MVA room for treatment. Those treated with D\&C are escorted to the main theatre where they are given pain control before treatment. MVA patients are generally not given any pain medication before or during the procedure. 
- New Nyanza Provincial General Hospital, Kisumu. Patients are admitted to the gynae ward in Kisumu and are treated with D\&C, which is typically done without pain medication. An MVA room was created several years ago adjacent to the gynae ward, and this is still used for treatment of incomplete abortion, though only D\&C was used during the baseline period of data collection.

- Meru District Hospital. Though classified as a "D\&C" site, during the course of data collection, Meru began to provide MVA services. Patients are admitted to the gynae section of the female ward, which is typically very crowded due to a high caseload of incomplete abortion patients. In the first period of data collection, patients were evacuated in main theatre, which caused long waiting times. Staff have now created an MVA room on the ward where patients are currently treated with MVA.

- Nyeri Provincial General Hospital. Incomplete abortion patients in Nyeri are treated with $\mathrm{D} \& \mathrm{C}$ in a minor theatre located just next to the gynae ward. Patients are generally treated fairly quickly, and pain medication is seldom used before or during the procedure. Just before initiation of this project and after a preliminary meeting with staff from the six hospitals, Nyeri began to provide postabortion family planning services based on the model planned for their site ${ }^{12}$. Since September 1995, patients have been escorted to the $\mathrm{MCH} / \mathrm{FP}$ clinic prior to discharge where they receive family planning counselling and methods. This is reflected in the findings from the baseline period, and so data for Nyeri are often separated from the other five hospitals.

\section{STUDY DESIGN}

The ultimate objective of this study is to test and compare the feasibility, cost, acceptability, quality and effectiveness of alternative approaches to providing emergency treatment of abortion complications integrated with family planning in Kenya.

The study utilizes a separate sample, pre-intervention post-intervention design. The interventions will be introduced through a combination of three general activities: 1) staff training in MVA and postabortion family planning; 2) facility upgrading; and 3) administrative and procedural reorganization. The findings in this report are from the pre-intervention period of data collection, which took place between February and July, 1996, and therefore are generally descriptive in nature, providing a picture of the current status of services.

\section{Field WORK AND DATA COLlection}

There was extensive preparation before the field work began. First of all, on completion of phase I (site selection), a dissemination/planning workshop was held in Nairobi for staff from the six hospitals chosen for the study as well as members of the reproductive health community. The purpose of this workshop was to sensitize staff to the concept of postabortion care and to create a true collaborative effort. One unanticipated result of the workshop was that staff from one site were so enthusiastic about the idea that they immediately went back to their hospital and began 
to provide postabortion family planning services following their model. Though this had an impact on the research design, it was quite encouraging in terms of creating sustainable services.

Two types of data collectors were recruited for the study: six researchers, one to be present at each site, to conduct interviews with providers and patients and collect service statistics; and three feasibility analysis researchers (FARs) to collect cost information at each site. All nine researchers were trained in administering the data collection instruments, which were pretested at Nyeri Provincial General Hospital. In addition, the FARs were trained to administer IPAS's A Guide to Assessing Resource Use for the Treatment of Incomplete Abortion ${ }^{13}$, a manual which directs the researcher to follow a patient throughout the course of her treatment at the facility. Researchers document the resources used for a patient (including bedtime, staff time, medicines used) to determine the overall cost of treatment to the facility.

Data for the baseline period were collected for six to eight weeks (depending on the caseload at the site) beginning in February 1996, with the six researchers present at the hospital continuously (except for weekends-- though in some sites, researchers remained during weekends when it was apparent that a number of patients were present at this time). The continuous presence of the researchers provided rich data. There is always a concern in collecting data on quality of care because of the bias created by the process of observation and the presence of an observer. However, it is felt that the information presented in this report provides an accurate picture of incomplete abortion services at the sites visited due to the long period of time spent at the sites. Table 2 provides a breakdown of staff and patients interviewed by site.

Table 2: Interviews conducted at each site ${ }^{14}$

\begin{tabular}{|lcccc|}
\hline hospital & staff & $\begin{array}{c}\text { patients-exit } \\
\text { (Feb.-March 1996) }\end{array}$ & $\begin{array}{c}\text { patients-exit } \\
\text { (May-June 1996) }\end{array}$ & $\begin{array}{c}\text { Total Patient } \\
\text { exit }\end{array}$ \\
\hline Eldoret & 26 & 61 & 19 & 80 \\
Kisumu & 22 & 30 & 21 & 51 \\
Meru & 22 & 37 & 38 & 75 \\
Mombasa & 17 & 58 & 35 & 93 \\
Nakuru & 20 & 59 & 62 & 121 \\
Nyeri & 33 & 59 & 2 & 61 \\
\hline TOTALS & $\mathbf{1 4 0}$ & $\mathbf{3 0 4}$ & $\mathbf{1 7 7}$ & $\mathbf{4 8 1}$ \\
\hline
\end{tabular}

14 These numbers do not reflect total caseloads at the sites, as women with gestations higher than 16 weeks LMP or those experiencing severe complications were not included in the sample. It is also important to point out that women sometimes wait so long that the abortion completes itself. These women did not undergo evacuations at the hospital and so were left out of the sample. 
Women arriving at the hospital with incomplete abortion, without serious complications and with gestations of 16 weeks LMP or below were selected to be included in the study ${ }^{15}$. Women were interviewed after obtaining verbal informed consent and only one woman refused to be interviewed. Caseloads were somewhat lower than expected based on data collected in phase I. Some providers attributed this to seasonal variations, while others felt it was partially a function of cost-sharing, which has been instituted in public hospitals in Kenya. Providers thought that this may have led to many people preferring to seek treatment outside of the public sector where even if it means paying more, they feel that they will be assured of quality care and availability of drugs.

During the baseline research period, an attempt was made to follow-up women three months after they left the hospital in order to assess their contraceptive use over time as well as document any possible complications they may have experienced after returning to their homes. Women were given the incentive of a free reproductive health exam (this included a pap smear, syphilis screening, pregnancy test, and blood grouping) and asked to return three months after their discharge from the hospital. The six researchers then returned to the hospitals for another period of six-eight weeks. Unfortunately, return rates were generally low, as indicated in table 3, with an overall return rate of 16 percent, ranging from a low of three percent to a high of 57 percent.

Table 3. Return rates of women interviewed during February and March, 1996

\begin{tabular}{|lcc|}
\hline \multicolumn{1}{|c}{ hospital } & $\begin{array}{c}\text { patients-exit } \\
\text { (Feb.-March 1996) }\end{array}$ & $\begin{array}{c}\text { patients-return } \\
\text { (May-June 1996) }\end{array}$ \\
\hline Eldoret & 61 & $11(18 \%)$ \\
Kisumu & 30 & $3(10 \%)$ \\
Meru & 37 & $21(57 \%)$ \\
Mombasa & 58 & $2(3 \%)$ \\
Nakuru & 59 & $9(15 \%)$ \\
Nyeri & 59 & $3(5 \%)$ \\
\hline \multicolumn{1}{|c|}{ TOTALS } & $\mathbf{3 0 4}$ & $\mathbf{4 9 ( 1 6 \% )}$ \\
\hline
\end{tabular}

Though the data are limited, they will be presented in this report to highlight some of the interesting issues that arose in the interviews. Because of the relatively low return rates, researchers had time to conduct additional interviews with new patients arriving at the hospital. These patient interviews were added to the initial pool of exit interviews, thus increasing the total sample size of patient exit interviews (see table 2). Analysis outlined in this report is based on this total sample size. Women interviewed during this second round were not asked to return to the hospital to participate in the study after three months (they were given whatever follow-up

Originally, women 12 weeks LMP or below were to be included in the study but, given that women often wait before seeking treatment at hospitals, this excluded a number of women. For the purposes of this study, it was felt that women with gestations of 16 weeks or less should be included in the sample, as these women were typically also treated with MVA at sites providing that service. 
appointments were part of hospital protocol). A discussion of the possible reasons for the low numbers of women returning is found later in the report.

This study involves a substantial service delivery component in planning for and implementing the interventions. As part of this, an IPAS representative visited each site to plan for site upgrading for MVA services. In May 1996, IPAS, the Division of Family Health (DFH) and FPAK conducted a training of trainers (TOT) in postabortion family planning. The trainers from this TOT then conducted the trainings for the six hospitals as part of the intervention in September and October, 1996. After the TOT, one of the sites organized a meeting for staff to create awareness of the concept of postabortion care. It was clear at this meeting that this is still a very new idea, with most people beginning with questions as to what exactly was postabortion family planning and how did it differ from regular family planning.

\section{FINDINGS}

Findings will be presented by following a hypothetical patient through her experience at the hospital. First, characteristics of patients and providers will be given. Data illustrating women's stay in the hospital will then be presented in the following order: the procedure; duration of patient stay on the gynae ward; pain control practices; infection prevention; provider-patient relations; information provision to patients; and postabortion family planning. The unique experience at Nyeri Provincial General Hospital will be briefly described. Patient costs of postabortion care services and findings from the follow-up period will also be presented. Finally, future plans and next steps for the study will be discussed.

\section{InCOMPlete Abortion PATIENTS: WhO ARE They? ${ }^{16}$}

Providers were asked to describe the "typical" woman who seeks treatment for incomplete abortion at their facility. In general, providers estimated that most women arriving for treatment have induced the abortion (70 percent) while approximately 30 percent seek care for a spontaneous abortion. They described the patients as young, ranging in age from 17 to 29 . Most providers ( 87 percent) describe the typical patient as being single, and almost three quarters (71 percent) say that this typical patient has no children. Roughly one fifth (19 percent) indicated a parity of one and nine percent a parity of two for the typical incomplete abortion patient.

How accurate is this perception? As table 4 indicates, patients actually have higher parity and are more likely to be married than providers describe. It is also notable that 22 percent of women were 30 years or older. Although these data are not directly comparable, the differences give some indication of the misperceptions about, and greater variety among, incomplete abortion patients, particularly regarding their parity and marital status. Almost one quarter (23 percent) of women interviewed indicated that they had experienced a previous pregnancy loss (women abortion was spontaneous or induced. It was felt that this information was not necessary for the purposes of this study, and that this would add to the stigma and differentiation that is already made between these two types of patients. For the provision of postabortion care, they require the same services; that is, treatment, counselling that is appropriate to their needs, and referral to any additional health services that are needed. 
were not asked whether this had been a spontaneous or induced abortion), and most of these had had either one or two other pregnancy losses, in addition to the current one.

Table 4: Characteristics of incomplete abortion patients

\begin{tabular}{|c|c|c|}
\hline characteristic & $\begin{array}{l}\text { provider perceptions } \\
\text { (\% describing typical patient } \\
\text { with characteristic) }\end{array}$ & $\begin{array}{c}\text { patient interviews } \\
\text { (actual \% of patients } \\
\text { with characteristic) } \\
\end{array}$ \\
\hline age/ age range: & 17-29 (mean) & 25 (mean) \\
\hline $15-19$ & & $18 \%$ \\
\hline $20-24$ & & $38 \%$ \\
\hline $25-29$ & & $23 \%$ \\
\hline $30-34$ & & $11 \%$ \\
\hline$>35$ & & $11 \%$ \\
\hline \multicolumn{3}{|l|}{ parity: } \\
\hline 0 & $71 \%$ & $33 \%$ \\
\hline 1 & $19 \%$ & $29 \%$ \\
\hline 2 & $9 \%$ & $15 \%$ \\
\hline$>2$ & $1 \%$ & $23 \%$ \\
\hline \multicolumn{3}{|l|}{ marital status: } \\
\hline married (monogamous) & $9 \%$ & $63 \%$ \\
\hline married (polygamous) & $0 \%$ & $8 \%$ \\
\hline single & $87 \%$ & $23 \%$ \\
\hline other & $4 \%$ & $6 \%$ \\
\hline
\end{tabular}

Women experience abortions for a variety of reasons; each arrives at the hospital with her own history. A few examples from the baseline research illustrate this point:

- a 17 year old girl was forcefully married to a man by her father, so that he could use the dowry paid to him to marry another wife. She was then raped by this man and when her father discovered that she was pregnant he gave her a large dose of malaria drugs and other tablets.

- a 21 year old separated woman with three living children said that she induced the abortion because she felt that she was too poor and that she cannot even send the three children she already has to school. She took bitter traditional herbs because she had no money to go to a private doctor to induce the abortion.

- a 25 year old married woman, this had been her fourth spontaneous abortion. She was pleased to receive the family planning counselling because it enabled her to ask questions and get advice, which she had previously not been given.

- a 30 year old married woman with three children. She had been secretly using the pill when she got pregnant, as her husband disapproves of family planning. She was very weak, having lost a great deal of blood. This had been her first pregnancy loss. 
- a 24 year old married woman had six pregnancies and three spontaneous abortions. She was determined not to become pregnant again because she felt that she had suffered a lot due to the miscarriages.

Understanding the circumstances which have compelled each woman to seek care at the hospitals can help providers to better counsel and generally treat women on their gynae ward.

Almost all women interviewed (97 percent) were familiar with family planning. Of these women, a significant proportion (22 percent) were using family planning at the time they became pregnant and either experienced method or user failure (figure 1). The main methods that had been used were the pill (42 percent), rhythm (36 percent) and condoms

\section{Figure 1}

\section{Patients' use/non-use of $\mathrm{fp}$ at time of last pregnancy}

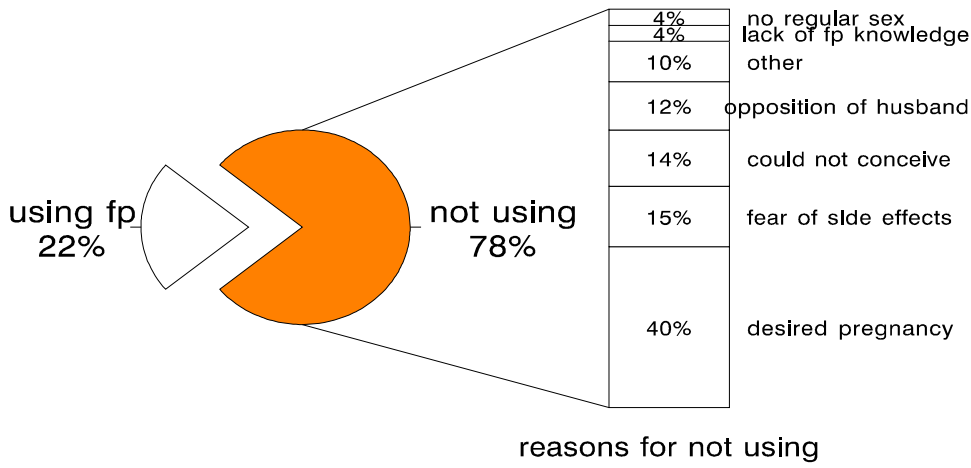

$(n=468)$ (seven percent), and almost half of these women felt that they had become pregnant because of incorrect or inconsistent use. In addition, over half of the women who knew about family planning (59 percent) had ever used a family planning method, with the pill most frequently mentioned, followed by the injectable, natural family planning and condoms.

It was also notable that 41 percent of women were accompanied to the hospital by their husband or partner. Because of this finding, husbands/partners of the women will be interviewed, if consent is obtained from both partners, during the post-intervention data collection period. This will provide valuable information on men's perspectives on postabortion care as well as ways to best incorporate women's partners into the care process.

\section{Profile of Providers}

One hundred and forty providers were interviewed. Of these, there were nine OB/GYN specialists, 23 medical officers, 14 clinical officers, five Matrons, and 89 nurses, seven of whom were in-charges of either the ward or $\mathrm{MCH} / \mathrm{FP}$ unit. Eighty were stationed in the gynae ward, 31 in the $\mathrm{MCH} / \mathrm{FP}$ clinic, 22 were in other units (this generally refers to theatre, as evacuations were performed in theatre in some of the sites), and seven were not specific to any one unit (i.e., Matrons). Of the 140 providers interviewed, 124 manage women who come to the hospital with incomplete abortion. "Manage" in this case means being involved in any of the following: performing or assisting with evacuation procedures; counselling about treatment; nursing care; or family planning services for incomplete abortion patients. Of the sixteen who do not directly manage incomplete abortion patients, six are matrons and eight from the $\mathrm{MCH} / \mathrm{FP}$ clinic. It should be noted that MCH/FP staff were interviewed, even though they might not directly 
manage incomplete abortion patients, since they will be involved at many of the sites in the provision of postabortion family planning services.

Over two-thirds of providers were married ( 69 percent), and 26 percent were single. The average age of providers interviewed was 34.7 . Two-thirds ( 65 percent) were Protestant, about one-third (31 percent) Catholic, and three percent Muslim. Just over half (51 percent) felt that the current law on abortion in Kenya is appropriate for the country, while 39 percent felt that it was too restrictive. The remaining providers either thought it was too liberal, or would not express an opinion. Of the group that said that the law was too restrictive, many felt that it should be legalized, while others thought that it should be allowed in more circumstances than it currently is, such as in cases of rape.

\section{The Procedure}

As mentioned earlier in this report, sites were designated as either "MVA" or "D\&C". As figure 2 shows, however, at some sites, both procedures were used with patients interviewed for the study, thereby indicating that these designations are not entirely accurate in their description of services. It is important to note that the data presented in Figure 2 are not based on theatre logbooks but rather on the procedures used with women interviewed for this study. Thus it does not necessarily represent the overall division of procedures at each hospital.
Figure 2
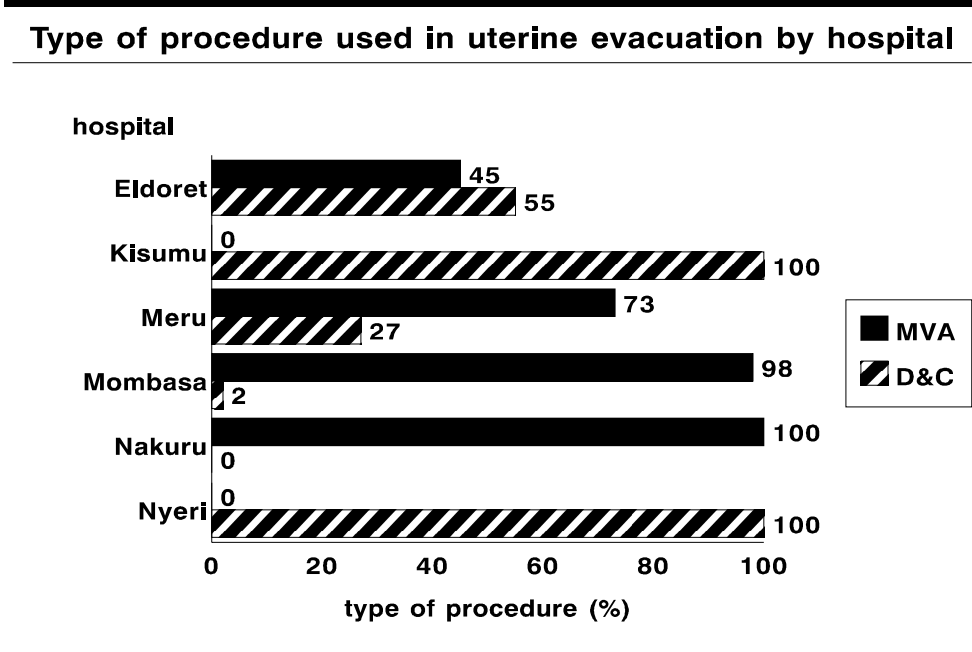

$(n=80 ; n=49 ; n=75 ; n=93 ; n=121 ; n=61)$

As figure 2 indicates, Mombasa and Nakuru treat most patients with MVA, while Nyeri and Kisumu relied on D\&C for the patients interviewed in this study. Eldoret, classified as an MVA site, treated just under half of the patients with MVA, while Meru, classified as a D\&C site in the beginning of the study, used MVA for almost three quarters of the patients. This points to the inconsistency in maintaining MVA services. Due to the lack of a national system of procurement and distribution of MVA instruments, hospitals have to rely on either donated equipment from various projects or individual initiative of providers to keep a stock of equipment. In the case of Meru, it also shows the need for more extensive training in use and handling of MVA instruments. The hospital had several kits, but had stopped using them several years earlier due to the lack of Cidex ( $2 \%$ glutaraldehyde) which they used to sterilize the instruments. When they were informed that JIK (chlorine bleach) could be used for high-level disinfection of the cannulae, they immediately began to provide MVA services again.

Just over one quarter of the providers interviewed have ever attended a training course in either D\&C or MVA (26 percent and 27 percent, respectively). However, a larger number had performed or assisted with the procedures in the three months preceding the interview, 41 percent 
and 30 percent, respectively. There are 28 providers who have performed or assisted with D\&C who indicate that they have not attended a training course on D\&C, while 18 providers indicate the same with MVA, although they most likely have received on-the-job training. Almost all of these providers are nurses: 25 of the 28 for $\mathrm{D} \& \mathrm{C}$, and 17 of the 18 for MVA. This is not surprising, as doctors typically receive training in these areas, but it points to the need to include nurses in these trainings so that they are better able to provide or assist with these services.

Those who had performed or assisted with D\&C and MVA were asked to name both positive and negative aspects of the procedure, and to describe their satisfaction with the procedures. There is generally greater satisfaction with MVA. Roughly twice the proportion are very satisfied with the MVA procedure (67 percent) as compared with D\&C (31 percent). Similarly, while 18 percent state that they are not satisfied with $\mathrm{D} \& \mathrm{C}$, only one provider says the same for MVA. As table 5 indicates, D\&C is praised for effectively removing products of conception (POCs), while MVA is viewed as an easy, cheap and fast procedure. While D\&C is considered risky due to the possibility of perforating the uterus, MVA is viewed as risky because of the potential for perforation or infection from unsterile equipment. Interestingly, a higher proportion of providers called MVA painful (37 percent) as compared with D\&C (19 percent) when citing negative aspects of the procedures. It should be noted that of the 99 providers who have performed or assisted with either MVA or D\&C, just under one quarter (23 percent) have performed or assisted with both procedures. Therefore, these findings should not be viewed as directly comparable.

Table 5: Positive and negative aspects of D\&C and MVA

\begin{tabular}{|c|c|c|c|c|}
\hline & \multicolumn{2}{|r|}{$\operatorname{D\& C}(n=57)$} & \multicolumn{2}{|r|}{ MVA $(n=42)$} \\
\hline \multirow[t]{5}{*}{ positive aspects: } & i. & $\begin{array}{l}\text { cleans out thoroughly leaving no } \\
\text { POCs }(47 \%)\end{array}$ & i. & $\begin{array}{l}\text { easy and convenient procedure } \\
(51 \%)\end{array}$ \\
\hline & ii. & $\begin{array}{l}\text { no pain since patients are sedated } \\
(14 \%)\end{array}$ & ii. & cheap $(35 \%)$ \\
\hline & iii. & $\begin{array}{l}\text { helps in diagnosing patients/ } \\
\text { procedure for biopsy }(12 \%)\end{array}$ & iii. & fast (33\%) \\
\hline & iv. & stops bleeding very fast (7\%) & iv. & safe $(28 \%)$ \\
\hline & & & $\mathrm{v}$. & no need for anesthesia (16\%) \\
\hline \multirow[t]{6}{*}{ negative aspects: } & i. & $\begin{array}{l}\text { risk of perforation of uterus or other } \\
\text { organs }(56 \%)\end{array}$ & i. & $\begin{array}{l}\text { risky-- perforations, infection } \\
\text { from unsterile equipment ( } 42 \%)\end{array}$ \\
\hline & ii. & postabortal complications $(33 \%)$ & ii. & painful $(37 \%)$ \\
\hline & iii. & painful $(19 \%)$ & iii. & $\begin{array}{l}\text { not effective for larger } \\
\text { gestations }(19 \%)\end{array}$ \\
\hline & iv. & can spread infection $(12 \%)$ & iv. & misuse of kits $(9 \%)$ \\
\hline & $\mathrm{v}$. & expensive $(7 \%)$ & $\mathrm{v}$. & kits expensive $(7 \%)$ \\
\hline & vi. & side effects due to anesthesia $(7 \%)$ & & \\
\hline
\end{tabular}




\section{DURATION OF PATIENT STAY ON THE GYNAE WARD}

Patients were asked to estimate the amount of time they waited while on the gynae ward to receive treatment. According to these estimates, patients tended to wait a long time between arrival on the ward and receiving treatment. This waiting time varied by the type of procedure used in treatment of the incomplete abortion. While over half of D\&C patients ( 56 percent) were treated within 12 hours, the same can only be said for 19 percent of MVA patients. Thirty-eight percent of MVA patients waited more than two days, while only 15 percent of D\&C patients waited for this long.

Studies have typically shown that MVA shortens total hospital stay, primarily because it can be done as an out patient procedure without use of general anesthesia ${ }^{17}$. Although this waiting time is not total hospital stay, the fact that MVA patients are generally waiting for longer periods of time before being evacuated points to the fact that there are many more issues than just the technology in terms of improving services and shortening hospital stay. As was found in the cost study cited above which was conducted in Kenya and Mexico, it is necessary to look at the whole organization of services, and not just the technology. As the authors of this study state, "the results suggest that patient management is the primary factor that contributes to the different levels of resource utilization required for the two procedures, affecting the time patients spend in the hospital as well as costs to the patient and ultimately the healthcare system."

Table 6: Patients' reporting of waiting time on gynae ward for procedure, by hospital ${ }^{18}$

\begin{tabular}{lcccccc}
\multicolumn{1}{c}{ hours } & Eldoret & Kisumu & Meru & Mombasa & Nakuru & Nyeri \\
\hline none & $15 \%$ & $0 \%$ & $5 \%$ & $0 \%$ & $0 \%$ & $0 \%$ \\
up to 12 & $45 \%$ & $51 \%$ & $5 \%$ & $5 \%$ & $13 \%$ & $89 \%$ \\
$\mathbf{1 3 - 2 4}$ & $24 \%$ & $19 \%$ & $11 \%$ & $18 \%$ & $34 \%$ & $2 \%$ \\
$\mathbf{2 5 - 4 8}$ & $11 \%$ & $19 \%$ & $12 \%$ & $29 \%$ & $24 \%$ & $2 \%$ \\
$\mathbf{4 9 - 7 2}$ & $5 \%$ & $9 \%$ & $15 \%$ & $22 \%$ & $18 \%$ & $3 \%$ \\
$>72$ & $0 \%$ & $2 \%$ & $51 \%$ & $26 \%$ & $12 \%$ & $2 \%$ \\
\hline
\end{tabular}

As shown in table 6, waiting time varied by hospital, again pointing to the importance of the organization of services. For example, while almost all patients at Nyeri (89 percent) were treated within 12 hours, over half of the patients interviewed at Meru (51 percent) waited for more than three days. The patients' estimates of long waiting times are confirmed by data from

\footnotetext{
17 Johnson, Brooke R., Janie Benson, Janet Bradley and Aurora Rabago Ordonez, "Costs and Resource Utilization for the Treatment of Incomplete Abortion in Kenya and

Mexico"Social Science and Medicine. Vol. 36, No 11. 1993 
the cost study. As described previously, this component of the study consists of following a patient throughout the course of her treatment and documenting the time she spends in the facility, as well as staff time, supplies and medicines used for the patient.

As figure 3 indicates, the duration of patient stay on the gynae ward varied a great deal by sites, from a low of 16.6 hours to a high of 75.9 hours. It is also interesting to note the difference in patient management, as noted in the breakdown between pre and post procedure time. For example, in Mombasa, the majority of a patient's stay is spent waiting for treatment. After she receives this treatment, she is discharged fairly quickly. In Nyeri, on the other hand, patients are treated almost immediately, then wait on average for 19 hours before discharge. This is due in part to the family planning services they receive, as patients are escorted to the MCH/FP clinic as a group generally in the morning.

It is worth noting that both Nyeri and Kisumu have a specific room on or near the ward where the procedures are performed, while, for most of the course of the baseline data collection period, both Mombasa and Meru used a shared theatre-- the VSC theatre in the case of Mombasa and main theatre in Meru. This tended to cause long waits due to the large number of other patients requiring treatment in the theatre. Both sites have now prepared, or are in the process of preparing, specific rooms on the gynae ward to provide incomplete abortion treatment. Having a specific room for the procedure is just one aspect of the picture. In Nakuru, although there is a room on the ward, there are still long waiting times. Some of the causes for these long delays, common to all sites, are the following:

- $\quad$ patient lacks money to pay for the evacuation, or lacks supplies, and must wait for relatives to bring them

- $\quad$ shortages of staff

- $\quad$ shortages of equipment (e.g., speculum) creating the need to wait for equipment to be sterilized

- $\quad$ shortages of MVA instruments which means that the time needed for adequate infection prevention translates into greater waiting time for the patients.

The long delays are closely linked to overcrowding in the wards, sometimes forcing two or three women to share a bed. This overcrowding leads to further delays in providing emergency treatment to women. Overall, the work becomes even more difficult for the gynae ward staff who must attend to large numbers of women at the same time. In general, these delays also increase cost to both the patient and the hospital. 


\section{Pain Control Practices}

One significant difference between treatment using MVA and treatment using D\&C is the way in which procedural-related pain is managed. In general, patients treated with D\&C are given general anaesthesia during the procedure such that they are asleep throughout the process. One of the advantages of MVA is that heavy sedation is not necessary, thereby making it a safer procedure for the patient. This also helps to lower the overall cost of the procedure to the hospital.

A common complaint from patients was the pain they experienced during the procedure. Fourteen percent of the patients were sedated and asleep during the procedure. In total, according to patient records, roughly onefifth (19 percent) of patients were given some sort of pain medication. This included only 44 percent of D\&C patients, despite the standard practice of sedating a woman during this procedure; three percent of MVA patients received some kind of pain medication. As shown in figure 4, of the women who were awake during the procedure, almost all (97 percent) reported experiencing pain. When asked whether the pain was 'extreme', 'moderate' or 'mild' about two-thirds indicated

\section{Figure 4}

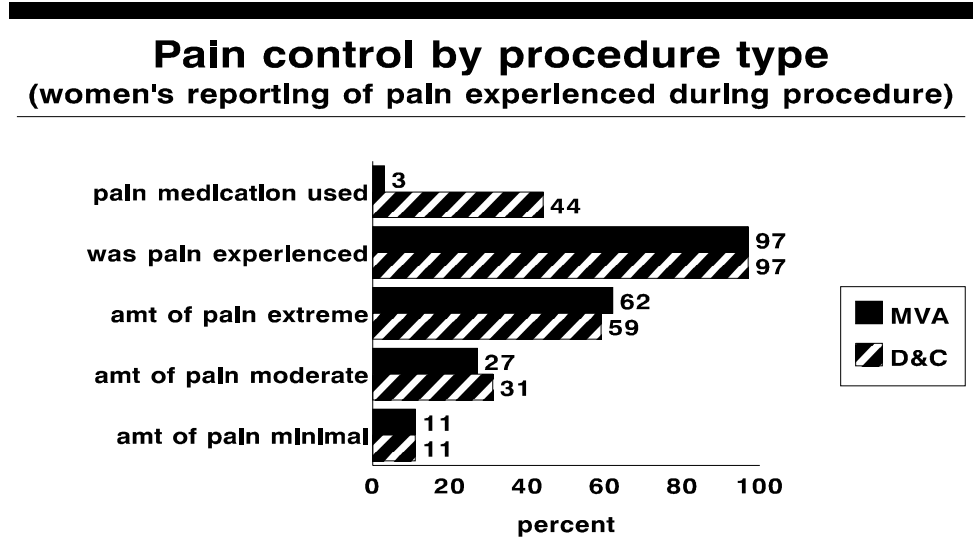

(for MVA: $n=303 ; n=294 ; n=285 ; n=285 ; n=285$ )

(for D\&C: $n=176 ; n=118 ; n=114 ; n=114 ; n=114$ )

pain experience for women who were awake during procedure that they felt an extreme amount of pain. For almost two-thirds, this pain was more than expected, while one-quarter said it was less than what they expected, and the rest said that it was what they expected. Interestingly, for patients who were awake during the procedure, for both MVA and D\&C patients, their description of pain experienced is almost identical.

Possible contributing factors for the pain include: fear, nervousness, hearing the cries of women treated before them as they wait to be treated, lack of counselling prior to the procedure, and lack of reassurance and counselling during and after the procedure. Providers at some sites were, however, attempting to rectify this situation even prior to the postabortion care training. At one site, for example, providers play music in the MVA room to calm patients.

The lack of counselling and reassurance of patients seems to be linked, in part, to the attitudes which some providers hold toward postabortion patients. Some, such as the provider cited below, use pain as a punitive measure: "I don't spare these young girls who become pregnant. They should be made to feel the worse pain so that they can fear having sex aimlessly." Others explained that it was too much of a problem to give pain medication because when patients are sedated they need to be carried to and from the procedure room and the whole care process is delayed. However, in the case of MVA, general sedation will not be necessary. 
At the dissemination workshop for these baseline findings, the issue of pain control was discussed with staff from the six hospitals involved. They indicated that the extreme pain which women experience is related to two factors: 1) the lack of general counselling, before, during and after the procedure; and 2) the bad technique practiced by some providers. The providers themselves agreed that they need to divorce their personal biases from their treatment behavior and that counselling was very important to reduce pain. In addition, most providers felt that pain killers should be used, staff should be trained in MVA and sufficient MVA kits should be provided to reduce waiting time and prevent the spread of infection. What kinds of pain medications to be used and when they should be administered should be fully clarified in the next phase of the project.

\section{InFECTION PrEvention}

Infection prevention (IP) is an essential component of health care, to protect both the patient as well as the provider. Providers who had ever performed or assisted with an MVA procedure were asked about general practices regarding reuse of MVA instruments, including decontamination, cleaning, sterilization and/or high level disinfection (HLD) as well as storage. If the hospital in which they worked was currently using MVA, providers were also asked about procedures used in that site. Table 7 shows their responses for general practices. Recommended practices are put in bold, while other responses are not recommended for handling MVA instruments.

Some providers indicated that they were using savlon or hibitane throughout the IP process, a practice which is not generally recommended given that these are low-level antiseptics which will not prevent possible infection. Decontamination, therefore, should be done in a $0.5 \%$ chlorine solution, which can be made with JIK. While most providers indicated that they were using JIK, the important point is to be sure that the solution in which the instruments are soaked is of a $0.5 \%$ concentration, which depends on the original concentration as well as the dilution factor.

Plain water, indicated by many providers for use in the cleaning stage of MVA instrument reuse, is even less effective than savlon or hibitane since it will not remove oils and protein. Instead water with detergent should be used when cleaning the syringe and cannulae in order to reduce the number of microorganisms on the instruments, thereby making HLD/sterilization procedures effective. Soap should not be used since it can leave a residue on the surface of the instruments.

Whether providers sterilize or high-level disinfect cannulae, savlon, hibitane and autoclaving should not be used. The antiseptics will not be effective at this stage and autoclaving the cannulae will melt and destroy them. While Cidex (2\% glutaraldehyde) is the only response given by providers which will sterilize equipment, Cidex, JIK ( $0.1 \%$ or $0.5 \%$ chlorine solution), or boiling for 20 minutes will effectively perform high-level disinfection on the cannulae. The latter technique, HLD, is recommended in sites where Cidex is not generally available for use. 
Table 7: General knowledge of infection prevention practices in the handling of MVA instruments

\begin{tabular}{|c|c|c|c|c|}
\hline $\begin{array}{l}\text { Decontamination } \\
\quad n=65\end{array}$ & $\begin{array}{c}\text { Cleaning } \\
\mathrm{n}=52\end{array}$ & $\begin{array}{l}\text { Sterilization } \\
\text { Cannulae } \\
\text { n=51 }\end{array}$ & $\begin{array}{c}\text { HLD } \\
\text { Cannulae } \\
n=60\end{array}$ & $\begin{array}{l}\text { Storage } \\
n=29\end{array}$ \\
\hline JIK $\quad(77 \%)$ & $\begin{array}{l}\text { Water and } \\
\text { detergent }(15 \%)\end{array}$ & $\begin{array}{l}\text { Cidex/ Totacide } \\
(22 \%)\end{array}$ & Cidex $\quad(32 \%)$ & $\begin{array}{l}\text { Wrapped in sterile } \\
\text { paper or cloth/ placed } \\
\text { in sterile box }(17 \%)\end{array}$ \\
\hline Cidex $(8 \%)$ & $\begin{array}{l}\text { Water and soap } \\
(17 \%)\end{array}$ & JIK $\quad(49 \%)$ & JIK $\quad(43 \%)$ & $\begin{array}{l}\text { Placed in sterile box } \\
(41 \%)\end{array}$ \\
\hline $\begin{array}{l}\text { Savlon, Hibitane } \\
(14 \%)\end{array}$ & $\begin{array}{l}\text { Savlon, Hibitane } \\
(10 \%)\end{array}$ & $\begin{array}{l}\text { Savlon, Hibitane } \\
(13 \%)\end{array}$ & $\begin{array}{l}\text { Savlon, Hibitane } \\
(5 \%)\end{array}$ & $\begin{array}{l}\text { Soaked in cidex, JIK, } \\
\text { or savlon }(42 \%)\end{array}$ \\
\hline \multirow[t]{2}{*}{ Formaldehyde (1\%) } & $\begin{array}{l}\text { Plain/tap water } \\
(48 \%)\end{array}$ & Boiling (2\%) & $\begin{array}{l}\text { Boiling } 20 \text { min. } \\
(8 \%)\end{array}$ & \\
\hline & $(10 \%)$ & Autoclave (14\%) & Autoclave (12\%) & \\
\hline
\end{tabular}

Lastly, the instruments must be stored appropriately to remain infection-free before subsequent use. Soaking the instruments in Cidex, JIK or savlon unnecessarily uses scarce resources and shortens the life of the cannulae and syringe. In general, syringes should be stored in a closed space, protected from dust and dirt, while cannulae should be wrapped in sterile paper or cloth and placed in sterile or HLD boxes until they are used again. As the findings indicate, there is a need to improve both knowledge and practices in this important area, and the trainings conducted with staff from the six hospitals in September and October, 1996 stressed infection prevention measures.

\section{Provider-PATIENT INTERACTIONS}

Findings from this baseline data collection indicated that negative provider attitudes towards incomplete abortion patients were quite widespread and seemed to be contributing to the poor quality of care received by patients. Provider attitudes come from and are reinforced by many factors, including their society's views towards abortion, the legal status of abortion, and the lack of resources in various health care settings. In Kenya, where abortion is illegal except to save the life of the woman, many people view women who have an induced abortion as "criminals". This then impacts on how patients are treated at the hospitals. As one provider explained, "the patients are generally handled as criminals or sinners because the staff make the collective judgement that every patient has induced [her abortion]."

Providers were asked to describe provider-patient interactions, and almost half (46 percent) described them as poor. Just over one-third (36 percent) said relations were good, while 15 percent said that it depends. Those who said the latter usually differentiated between women with induced or spontaneous abortions. As one provider expressed it, "proved induced abortion patients are automatically harassed but spontaneous cases are sympathized with, although sometimes it is difficult to know." 
It was also apparent that these strained interpersonal relations were created by the interaction between provider and patient attitudes. Women arrive at the hospital afraid, cautious, needing to buy supplies, expecting poor services. Staff are overworked, underpaid, have little access to needed supplies, they are frustrated and see women as having done something illegal and selfinflicted for which they (the staff) must now work hard to alleviate. The following quotes illustrate the situation:

- $\quad$ "There is that general mistrust between patients and staff, most patients lie, so we have to be quite tough on them"

- $\quad$ "Some nurses are frustrated by the working conditions such that some direct their anger towards the patients"

- $\quad$ "The patients themselves have that hidden hostility towards the staff such that they can even exchange bitter words with them. This is because patients feel that nurses are the ones denying them supplies such as cotton, medicine or any other things which they are told to buy"

As figure 5 indicates, these provider and patient attitudes create an atmosphere where open communication is blocked. This then leads to patients not communicating to providers, often leading to providers being harsh and sometimes negligent with the result of poor quality of care for the patients. For example, patients are made to wait long periods of time, they are made to clean bathrooms, and they are generally given very little attention. The potential health outcome of all of this is increased morbidity and mortality, as well as repeat abortion rates, as these patients get little to no counselling on how to avoid the problem that brought them to the hospital. It can also lead to patients leaving without getting proper treatment.

When patients were asked what they would do to improve services at the hospital, the most common response, mentioned by 25 percent, was to have staff change their attitudes towards patients and to stop harassing them. At the dissemination workshop, staff proposed the following to address the issue of negative provider attitudes:

- $\quad$ Train staff on postabortion care and staff-patient relationships

- $\quad$ Staff should be polite and understanding to the patients, rather than judgmental

- $\quad$ A forum for staff dialogue should be set up at sites. Some suggested the use of COPE ${ }^{19}$, so that staff can share their experiences with one another and those with good attitudes can influence the others

- $\quad$ Supply provision should be improved, pay increased and more training given, all to act as motivating factors

- Providers should have a definition of standard care that is strictly enforced by the hospital administration

- Providers should look at patients as patients, not as "induced" or "spontaneous" cases

19

COPE, which stands for client-oriented, provider-efficient services, is a self-assessment technique introduced by AVSC which hospitals and clinics can use to make their services more efficient and more responsive to client needs. COPE. Client-Oriented Efficient Services, AVSC International, New York. 1995. 
Figure 5: Interaction of patient and provider attitudes, its impact on behavior and potential health outcome

ENVIRONMENT: negative views towards abortion, legal status of abortion, cultural and religious factors, lack of resources for health care.

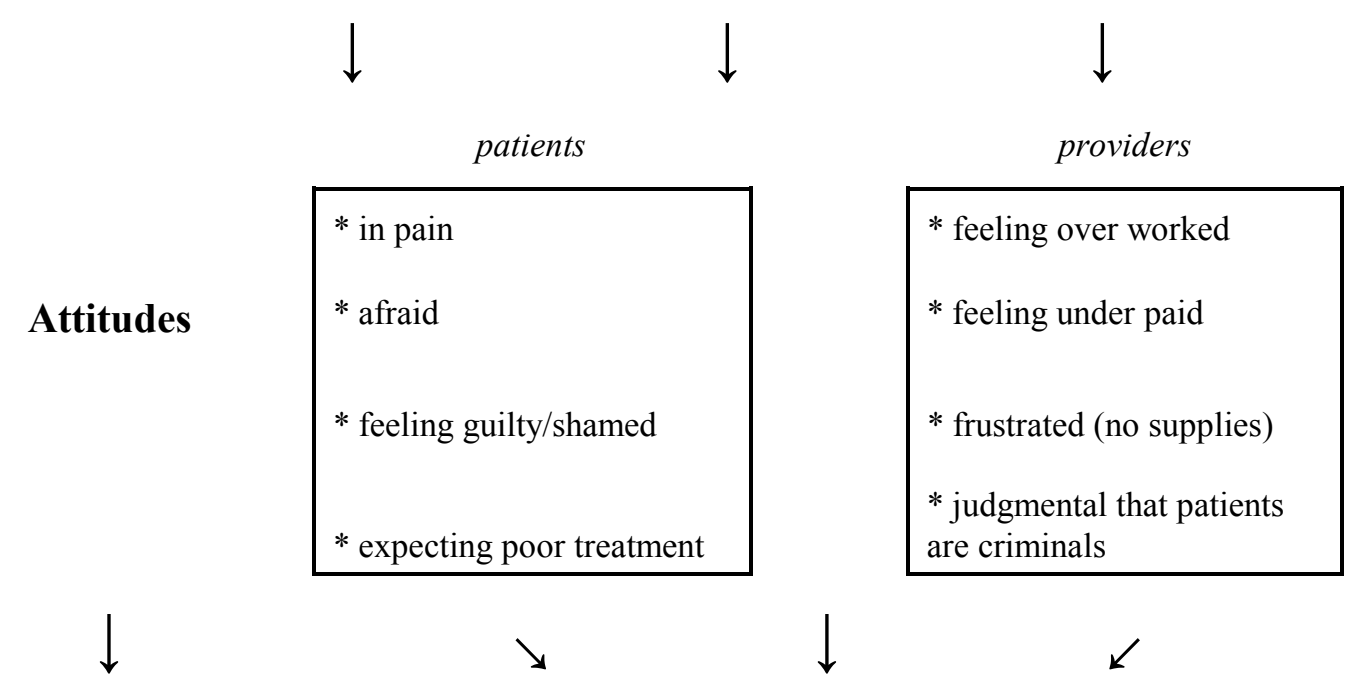

Atmosphere<smiles>[CH][CH]</smiles>

Behavior

Potential lack of communication/trust

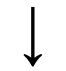

poor quality of care:

provider negligence, patients refusing to give information

long waiting times, absence of counselling

\section{Outcome}

\section{InFORMATION Provision To PATIENTS}

One of the key elements of quality of care is information exchange between providers and patients. It is essential for providers to both give information to and obtain information from patients in order to meet the patient's health needs. This was found to be lacking in the baseline study, as shown in figure 6. Patients were asked if they received information on a number of issues. It is particularly striking that only two percent of patients indicated that they received any information on problems that they might experience for which they should return to a health facility and only seven percent were told what to do if they developed a problem after discharge. 
Sixteen percent were told by a provider that they could have an almost immediate return to fertility. This is reflected in the fact that when women were asked when they could become pregnant again, 59 percent said that they did not know. As one patient explained when discussing information given to her by providers, she said she was "just told to go away since I'd been a bother."

Only 18 percent of women were told what was going to happen to them during the procedure. This can clearly add to the stress of the situation for the patients, especially in sites where patients are treated in main theatres. The patients can feel like they are about to undergo a major surgical procedure. As one researcher explained, "theatre means something major" and she saw some women "trembling because they were scared when they were told at the last minute to go to theatre." If the patients were adequately informed about what was involved in the procedure, their stress could be greatly reduced. As noted above, this lack of information giving could possibly be attributed to provider attitudes, lack of training and the generally busy and crowded nature of many of the wards. Clearly, in addition to creating linkages to postabortion family planning counselling, there is a need to improve general counselling of incomplete abortion patients.

One factor that can lead to low levels of information provision is lack of knowledge among providers. Therefore, providers were asked questions to assess their knowledge of complications from abortions and the return to fertility among incomplete abortion patients. In general, there was fairly low knowledge, which could partially be accounted for by inadequate training. For example, providers were asked to name problems after an evacuation for which a woman should return to a health facility. Just over half (55 percent) could name bleeding more then normal menstrual bleeding, almost half(46 percent) mentioned severe or increased

\section{Figure 7}

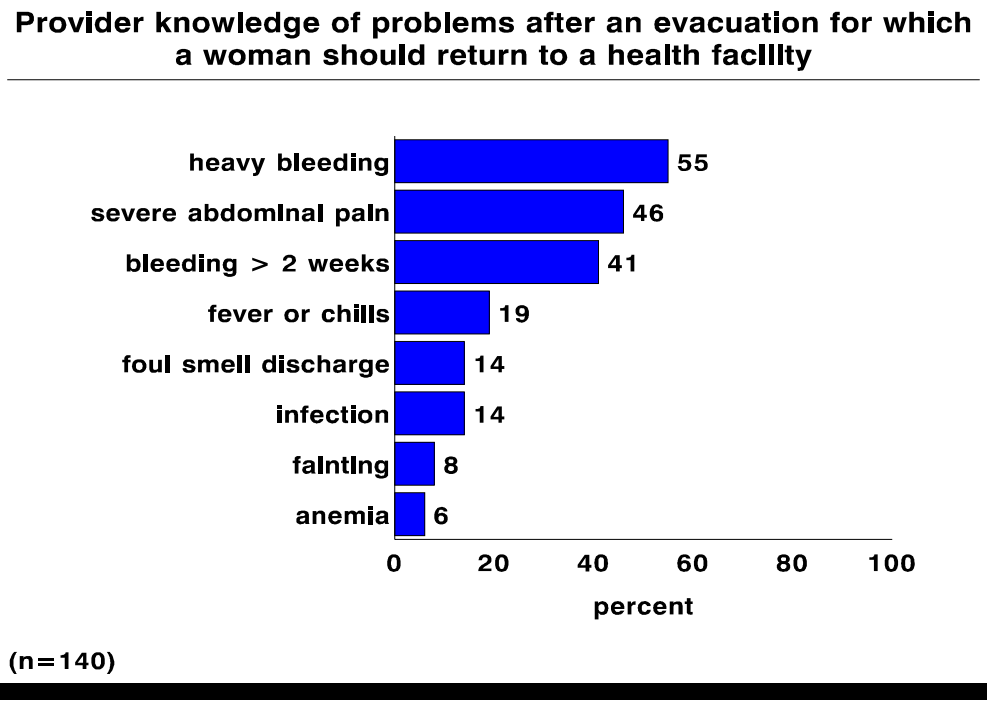


abdominal pain, and 41 percent knew about bleeding for more than two weeks. Other potential problems were much less frequently mentioned (figure 7).

In addition, most providers were not aware that a woman can return to fertility almost immediately following an incomplete abortion. On average, providers said that a woman's fertility returns about six weeks after either a spontaneous or an induced abortion.
Figure 8

Attitudes of Staff Regarding Postabortion Family Planning and Actual Provision of Services

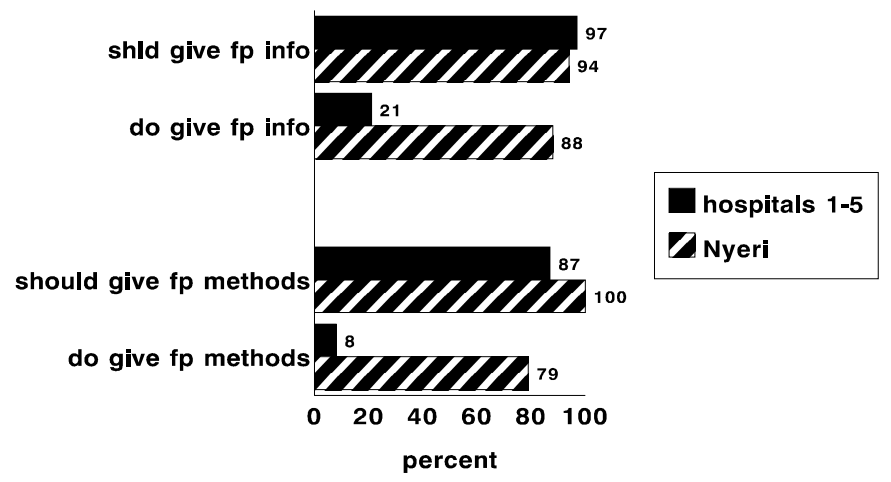

(for hospitals 1-5 $n=107$; for Nyeri $n=33$ )

\section{Postabortion Family Planning}

There is clearly a need and a demand for postabortion family planning, as indicated from both patient and provider comments. Of patients who did not receive family planning information, the majority ( 89 percent) would have liked to. In addition, there were many women who indicated a desire to either space or stop their births, yet few were using a family planning method or had accepted a method during their hospital visit. Twenty-three percent of women would not like to have any more children, while 22 percent would like to wait one to two years for their next child, and 20 percent would like to wait more than two years.

As shown in figure 8, there is also wide agreement among providers of the need to provide postabortion family planning. However, in general, these services are not currently being offered, except for in Nyeri. Information for Nyeri is presented separately to show the differences between it and the other five hospitals.

Patients were asked if anyone spoke with them about family planning (figure 9). For five of the hospitals, only seven percent were given information on family planning, while at Nyeri, almost every patient interviewed $(98$ percent) said that she had received information. While only 22 percent decided to begin using family planning at the five hospitals, at Nyeri this number was 62 percent. Of these who decided to use family planning,
Figure 9

\section{Provision of Family Planning Services} to Incomplete Abortion Patients

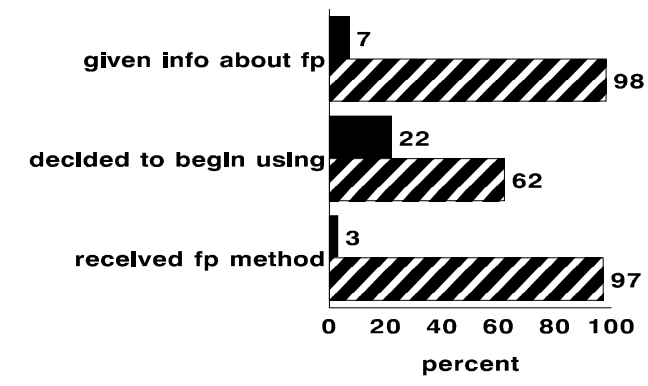

Hospitals 1-5

Nyeri

(for hospltals 1-5 $n=419 ; n=419 ; n=90$ )

(for Nyeri $n=61 ; n=61 ; n=38$ ) 
three percent received a method, while at Nyeri almost all who decided to begin using received a family planning method (97 percent).

\section{The Experience Of Nyeri Provincial General Hospital}

As stated earlier, staff from Nyeri Provincial General Hospital began to implement postabortion family planning services at their hospital immediately following the August 1995 dissemination workshop. Following their model, patients were escorted from the gynae ward to the family planning clinic where they received counselling and methods, if they so chose. They were then brought back to the gynae ward and discharged. Patients and staff were therefore asked the postintervention section of the questionnaire as they were already involved in postabortion family planning services. In general, both staff and patients seemed very satisfied with these new services.

Providers were asked a series of questions to assess the acceptability of the new services. Of the thirty-three providers interviewed, twenty indicated that they now had new responsibilities. All twenty felt that these new responsibilities were acceptable. They were also asked specifically about the timing, location, staff offering the services and any problems encountered with the new services. Most ( 85 percent) felt that the timing-- after evacuation and before discharge-- was appropriate. Almost all (94 percent) felt that the family planning nurses were the appropriate staff to be delivering postabortion family planning services.

Location was not as universally approved; just under two-thirds (64 percent) of staff felt that providing services in the family planning clinic was acceptable to the staff. Of the twelve providers who indicated that it was not appropriate, seven were from the gynae ward and five from the MCH/FP clinic. Most of these 12 providers explained that they thought services should be offered either on the ward or in a room near the ward. Some pointed out that the clinic was too far for patients, while others felt that incomplete abortion patients needed more privacy, as they "do not feel free mixing with the mothers because some are young girls who want anonymity."

Eight of the providers ( 24 percent) said that they had encountered problems in implementing postabortion family planning services. The problems they identified included clients' refusal to use family planning, shortage of equipment, shortage of staff and congestion in the MCH/FP clinic. Half of these providers felt that they had been able to address the problems adequately.

Almost all (98 percent) of the patients stated that they were given information on family planning. Of the 62 percent of patients who decided to use family planning, all but one (97 percent) received a method. The vast majority of women accepting a method received the pill (86 percent), while a small number chose the injectable (11 percent) and one woman opted for female sterilization. Most women ( 84 percent) were told about methods other than the one they chose. Though roughly one-third (35 percent) would have liked a different method, only one woman was disappointed that she did not get the method of her choice.

Women seemed generally satisfied with the family planning services, which they received in the family planning clinic after evacuation. All of them felt that both the timing and location were 
appropriate. Almost all (93 percent) felt that they had enough privacy, and most ( 77 percent) felt that the consultation time was the right length. Of those women who had questions (47 percent), they all felt that they were able to ask them and that they received an adequate response to their questions.

This gives a glimpse of some of what we might expect after the interventions are implemented at all sites.

\section{Costs Of Postabortion Care}

Many studies have looked at the high costs to hospitals in treating incomplete abortion cases. They often account for the vast majority of gynecological admissions, and as noted above, often spend several days in the hospital. A cost component was conducted as part of the baseline study to be used to provide pre and post comparisons after the new services are introduced, and to provide cost comparisons between the three different models of postabortion family planning. Details of this will be presented in the final report to describe these comparisons.

In addition to the analysis of costs to the hospital of providing services, patients were asked how much money they spent to receive services. Due to cost-sharing at Kenyan government hospitals, almost all patients interviewed (99 percent) paid for services. First of all, they paid for the evacuation. This was either 80 Kenyan shillings (Kshs),100 or 150, depending on the site and on use of D\&C or MVA ${ }^{20}$. Patients also paid per day for a bed (roughly Kshs 40), had to buy their drugs (Kshs 20-30 per drug), and paid for supplies, such as disinfectant (e.g., a bottle of JIK, a local disinfectant), gloves and gauze. A common complaint from patients was this need to buy all of their supplies; in making suggestions for improving services, 16 percent of patients said that they should make supplies available so that patients would not have to buy them.

On average, patients paid $440 \mathrm{Kshs}$ for treatment (roughly US\$8). This varied by hospital, ranging from a low of Kshs 200 (Kisumu), Kshs 310 (Nyeri), Kshs 407 (Nakuru), Kshs 455 (Mombasa), Kshs 500 (Eldoret) and up to a high of Kshs 712 (Meru). This cost includes hospital fees (evacuation, bed, drugs), purchasing supplies and travel costs. There is a connection between duration of hospital stay and patient costs, as the hospitals where the patients paid the most are also the hospitals where the patients spent the longest time on the gynae ward. Almost half of the women (45 percent) thought that the cost of obtaining services was acceptable, while one third (32 percent) thought it was much too expensive, 15 percent said it was a little too expensive and seven percent did not know. These figures should be viewed as rough estimates, as often patients did not know that exact cost for certain items, as someone else was paying for them. 


\section{FOLLOW-UP INTERVIEWS}

As indicated earlier, few women returned for follow-up interviews at three months. Possible reasons to explain why women did not return include the following: the generally poor treatment of patients; distance to the facility; stigma; and the difficulty in returning for women who work ${ }^{21}$. Interestingly, there were significantly higher return rates at Meru District Hospital, with 57 percent returning as compared with between three and 18 percent at the other hospitals. It is unclear why there was such a difference, though it could be explained by provider behavior, or the smaller area served by the hospital, or other reasons.

There were two common reasons cited by women for returning to the hospital for the follow-up interviews: they wanted the problem which had caused the pregnancy loss to be identified and treated through the reproductive health exam (61 percent); and/or they were told to return, referring either to the researcher or more often the doctor (55 percent), as "one must do what the doctor says". When asked if the offering of the free reproductive health examination affected the decision, the majority (71 percent) said yes, again emphasizing their desire to see if they were ok. There is a clear indication that women with spontaneous abortions really want information on why it happened and what they can do to avoid future problems. This points to the importance of the third element of postabortion care-- links to other reproductive health services- as many spontaneous abortions are linked to STD infection.

This strong concern for their health among incomplete abortion patients is similar to findings from a postabortion care study carried out in Egypt ${ }^{22}$. This study found that "for all types of postabortion patients the most salient issue, however, was their physical survival of an extremely painful experience." They also expressed a need to regain "bodily order". However, since such a small proportion of women returned for the health exam, there is no way of knowing how much of a deterrent it was to those who did not come back.

Because pain played such a dominant role in most women's experience at the hospital, several questions were asked to see how the experience was recalled after the passage of time. Just over half (55 percent) said they had felt pain. Few of these patients had received pain control, and all those who had not would have been willing to pay for it. As one woman explained, "after all, I bought other necessities, why not pain medication?"

Most women discussed their treatment with someone after leaving the hospital, with husband or partner most frequently mentioned (63 percent). About one half ( 49 percent) mentioned a friend, 37 percent discussed with their mother and 39 percent with another relative. Generally, women described reactions as being positive and supportive, though some women complained of being treated poorly as people assumed the abortion was induced. As one woman explained, "some friends come and tell me so and so was saying you were pregnant and you removed [induced].

\footnotetext{
21 For example, one teacher could not get leave and had to fight with her headmaster and get a note from the hospital in order to come back Associated with Abortions in Egypt. Final Report. The Population Council. Cairo. 1995.
} 
This has really made me hate these people." There were also indications of women with spontaneous abortions receiving negative reactions. For example, one woman said that while"some sympathized, others said it was a problem of my own making because of overworking."

Because of the low numbers of women returning, the follow-up interviews will be dropped from the post-intervention data collection period. Unfortunately, data will not be obtained on continuation rates in use of family planning or on complications experienced post-treatment. These are important issues for further research.

\section{Dissemination Workshop And Future Plans}

A workshop was held in Nairobi in August 1996 with staff from the six hospitals involved in the study as well as a number of members of the reproductive health community. These findings were presented and participants focussed on the following issues and developed recommendations to address each: pain control, provider-patient relations and infection prevention.

In addition, plans were finalized for the MVA and postabortion family planning trainings which were conducted in September and October, 1996. Short site reports were prepared for staff at each hospital focusing on key findings and descriptions of services at their hospital. Postintervention data collection will take place in March-April 1997 and findings will be widely disseminated, both nationally and internationally. Findings will help inform planning in the $\mathrm{MOH}$ for expansion of postabortion care services throughout the country. 